\title{
A Study on Reticence in College EFL Classrooms: The Role of Diffusion of Responsibility
}

\author{
Yun Zhou ${ }^{1} \&$ Yijin Chen ${ }^{1}$ \\ ${ }^{1}$ School of Foreign Languages, Zhejiang University City College, Hangzhou, China \\ Correspondence: Yun Zhou, School of Foreign Languages, Zhejiang University City College, Hangzhou, China
}

Received: May 1, 2020

Accepted: May 28, 2020

Online Published: May 29, 2020

doi: 10.5539/elt.v13n6p133

URL: https://doi.org/10.5539/elt.v13n6p133

Project Sources: This work is supported by Zhejiang Provincial Social Science Foundation of China No. $18 N D J C 173 Y B$.

\begin{abstract}
The absence of students' willingness for classroom participation is known to lead to a lose-lose situation where teaching schedules are disrupted, teachers lose enthusiasm, and students hardly learn anything. The problem is plaguing Chinese college EFL teachers as much as it did decades ago. Large quantities of studies have tackled the problem; however, little research has considered how students' psychology might link to classroom reticence. One psychological factor accountable for inaction when in the presence of a group of people is diffusion of responsibility. Thus, this study explores whether diffusion of responsibility plays a part in college EFL classroom reticence and whether there are any associations between diffusion of responsibility and gender, or English proficiency, or question type, or class size. Data from a questionnaire, interviews, and classroom observations showed that diffusion of responsibility was indeed a cause for class reticence. Further, Spearman correlation analyses found that no correlation existed between diffusion of responsibility and gender, or English proficiency. Paired-samples t-tests showed class size did have an impact on diffusion of responsibility while question type did not make a difference. Several suggestions on containing diffusion of responsibility and building rapport were put forward. The results should assist EFL teachers to work out possible solutions to the problem of class reticence.
\end{abstract}

Keywords: class reticence, diffusion of responsibility, psychological factors, college EFL class

\section{Introduction}

Engage, study and activate are the three basic elements of an effective teaching model known as ESA (Harmer, 2000). Teachers may conclude with the activating stage when utilizing ESA. Some activating activities include role-playing, debating, story building tasks and discussions. Activating exercises offer students opportunities to try out real language use and activate their knowledge. It is also very important to help teachers know how well their students have learned. However, in college EFL classes in China, teachers' playing a monodrama has gradually become a normal state. Most students are silent and lack the motivation and initiative to participate in class, which hinders the development of their English language ability. Affected by this, teachers get frustrated, classroom atmosphere becomes dull and learning efficiency is impaired. The phenomenon of reticence in college EFL classroom often results from failure of communication between teachers and students, which reflects the negative psychology of students who are not interested in the class or even antagonistic to a certain extent. The phenomenon has raised researchers' attention. It is urgent to figure out possible causes for the problem and give enthusiasm back to class.

\subsection{Research Background}

Class reticence has always been a problem in large-sized college EFL classes in China. Students in such a class are generally divided into three types. The first type is eager to learn, actively engaging in class interaction thus becoming the main force to mobilize the classroom atmosphere. The second only aims to pass the final exam, and never bothers to join any class activities. And the third consists of the majority of reticent students in the class. They have good grades and cheerful personality. Even if they know the answers to the teacher's questions, they seldom look up at the screen or teacher and usually keep silent. If this group can be mobilized, classroom 
atmosphere will be greatly improved. At present, most research on the causes of reticence in college EFL classes focuses on classroom atmosphere, teachers' questioning methods and the influence of traditional culture. Little attention is paid to students' psychology. A socio-psychological phenomenon termed "diffusion of responsibility" explains why individuals are less likely to take action when a large number of people are present. This is pertinent to EFL classes in China in view of their large class size. Therefore, this study aims to investigate the cause of reticence in college EFL classes from a psychological perspective, namely diffusion of responsibility, and further explore whether this psychological phenomenon is related to such factors as gender, English proficiency, question type, and class size. Hopefully the findings could help EFL teachers come up with countermeasures for breaking silence and creating efficient interactive classroom.

\subsection{Research Questions}

This study tries to answer three research questions:

1) Does diffusion of responsibility play a role in causing reticence in the college EFL classroom?

2) If yes, are there any associations between diffusion of responsibility and gender, or students' English proficiency?

3) Are there any significant differences by question type or class size in diffusion of responsibility as a reason for class reticence?

\section{Literature Review}

\subsection{Previous Studies on English Classroom Reticence}

Most previous studies discuss reticence in college EFL classrooms from five aspects. Only a small number of studies shed light on the concept of diffusion of responsibility and how it influences students psychologically.

Researchers have drawn great attention to teachers' questioning strategies. Wang and Zhang (2008) described a situation when sometimes teachers' questions were too unfamiliar to answer but sometimes too simple and boring and little time was given for preparation. Zhang and Zhang (2009) revealed that teachers always controlled the subject, content and process of a topic, which made students become passive in class. In addition, $\mathrm{Hu}$, Nielson and Chen (2004) emphasized that the distribution of questions were mostly in the front and center part of the classroom which violated the principle of "equal opportunities".

Current studies show that classroom environment is also a major reason for reticence. In Osterman's study (Osterman, 2014) on some Japanese students, he found there was a negative understanding about the classroom atmosphere even before they entered class. And later other students' actions in class (sleeping, using Japanese, or not paying attention) reinforced their negative belief. Soo and Goh (2013) held the opinion that most of the students believed feelings of anxiety was the major obstacle to oral participation in ESL classroom.

Moreover, many studies have identified students' English proficiency as one of the factors responsible for class reticence. Liu and Jackson (2009) pointed out the more proficient in English the students were, the more willing they were to participate in speech communication and the more positive they were about it. Furthermore, Alemi, Tajeddin and Mesbah (2013) indicated that advanced students were more willing to initiate communication in second language than the intermediate ones. They also found that learners who had communicated with foreigners manifested a higher degree of willingness to communicate with English speaking people. This could also be an evidence to support the idea that students with higher English proficiency were more active in class because they have improved their English through communication with foreigners.

Besides what has been mentioned above, scholars have associated Chinese students' silence with their culture heritage. Zhang and Head (2010) presented the idea of "face", which required people to protect each other's self-image and feelings. They also stated that a person with authority in Chinese culture, like teachers, was seen as having a caring, nurturing, and benevolent role that cannot be questioned. Li and Liu (2011) mentioned in their study that Chinese culture always valued the collective over the individual, whose people could never separate themselves from obligation to others. Harumi (2011) indicated that some learners thought they should respond or express themselves only when they were nominated individually. However, Peng (2014) challenged the stereotype of Chinese students as 'passive' learners in communicative language classrooms and pointed out Chinese students were active and cooperative learners based on Confucian philosophy.

Another explanation for students' reluctance to speak in class is the relationship between students and teachers. This is because the interaction between teachers and students in the classroom can also be regarded as a social activity, which affects students' attitudes towards learning. If the relationship is harmonious, the classroom atmosphere will be more dynamic, and students will be more willing to participate. In the research of Cao and 
Philp (2006), learners reported greater willingness for participation among friends than with unfamiliar classmates.

\subsection{Diffusion of Responsibility}

Diffusion of responsibility is a psychological phenomenon in which people are far less likely to take responsibility for action when in the presence of a large group of people (Kassin, Fein, Markus, \& Burke, 2013) (Beyer, Sidarus, Bonicalzi, \& Haggard, 2017). For example, in emergency situations, individuals feel less motivation to respond or call for help if they know that others are present. A series of studies have been conducted to model, predict and intervene diffusion of responsibility among group members under social conditions. Relatively little attention has been given to the role of diffusion of responsibility in classroom reticence. Karp and Yoels (1976) identified a college classroom norm as "the consolidation of responsibility" where a few students assumed the responsibility of being active participants in the classroom with the majority of students being passive observers or only occasional participants. Cao and Philp (2006) mentioned willingness to speak was largely influenced by the number of participants and the sense of responsibility to communicate was reduced in whole class context. According to the study of Wu (2016), students' failure to establish a sense of responsibility underlay their slackness in class.

\section{Methods}

\subsection{Participants}

This study was conducted during the fall 2019 semester in a southeastern Chinese university where 118 freshmen from College English (III) class were involved. There were 19 male students and 81 female students. These students were non-English majors and their English proficiency levels ranged from high to low based on their scores in the college entrance exam. The reasons for choosing them are as follows:

1) The students of College English (III) come from different majors. The diversity of participants in this study ensures the credibility and validity of data to be collected to a certain extent.

2) Freshmen are more likely to have an unbiased opinion about their courses because they are new to college study. So, the results from the questionnaire and interviews are generally considered reliable.

Participants signed consent forms when agreeing to participate in the project, and were informed that the results of the project might be used in future publications.

\subsection{Instruments}

This study adopted a mixed-method approach. The research instruments included a questionnaire, one-on-one interviews and classroom observations. This triangulation of methodologies allows us to overcome some of the limitations of any single method (Denzin, 1989).

A questionnaire was developed to collect students' perceptions of reasons for class reticence and possible solutions to the problem. The four-part questionnaire consisted of 20 questions. The first part collected demographics of the participants. The second part aimed to answer the first research question, offering a list of 13 reasons for class reticence. The third part was designed to investigate the second and third research question by asking students to choose reasons for their reticence in two sets of scenarios: 1) when the assignment was given to the whole class or small groups of four students, 2) when the question was a factual one or opinion one. A factual question is defined as a question with a fixed or standard answer, such as the answer to a multiple choice reading comprehension question while an opinion question means an open-ended question. All scenarios were based on the precondition that the students knew the answers to the questions. The fourth part was two open-ended questions concerning other possible reasons for class reticence and suggestions regarding solutions to the problem.

Semi-structured interviews were mainly intended to discuss reasons for class reticence and possible solutions to the problem. The interview questions are: 1) Why do you sometimes keep silent when you actually have the ability to contribute to class activities? Is question type (factual or opinion questions)/task type (class work or group work) a concern? 2) Were there moments when you decided to speak up at the beginning but changed your mind when you saw fellow students kept silent? Why did you hesitate? 3) Would you take a more active or less active part in class participation if your class becomes a smaller one with only 20 students? 4) What are some possible reasons for your fellow students' silence in class? 5) What are your suggestions for solving the problem of college EFL class silence?

Classroom observations focused on students' typical classroom behavior under whole class discussion, group discussion and pair-work. The purpose was to offset any possible bias which might come from students' 
self-reported reasons for class reticence.

\subsection{Data Collection}

The questionnaire was administered to 118 participants and data from 100 valid questionnaires were processed by SPSS 18.0. Descriptive statistics were used to calculate the frequency of suggested reasons in order to ascertain whether diffusion of responsibility played a role in students' silence. Then, Spearman's correlation was conducted to investigate associations between diffusion of responsibility and gender, or English proficiency. Paired-samples t-test was run to determine any significant differences in diffusion of responsibility under different conditions of question type, or class size.

We took part in two 90-minute class sessions for classroom observation, during which pictures and observation notes were taken for reference to some of the interview questions.

Finally, we conducted one-on-one interviews with 10 volunteers including 8 female students and 2 male students. Each interview lasted 10 to 15 minutes, and with permission, was recorded and transcribed afterwards.

\section{Findings and Discussion}

\subsection{Whether Diffusion of Responsibility Plays a Role in Students'Silence}

Table 1. Descriptive statistics of the reasons for class reticence

\begin{tabular}{|c|c|c|}
\hline Type of reason (total percentage) & Description of reason & Percentage \\
\hline \multirow{4}{*}{$\begin{array}{l}\text { Type A: diffusion of } \\
\text { responsibility }(13.68 \%)\end{array}$} & I bet I won't be picked to answer the question. & $6.22 \%$ \\
\hline & $\begin{array}{l}\text { Most people keep silent, and what most people do is } \\
\text { always right. So I won't be the only student to blame. }\end{array}$ & $3.73 \%$ \\
\hline & $\begin{array}{l}\text { There will always be several outstanding students to } \\
\text { answer, so I don't need to speak out. }\end{array}$ & $2.49 \%$ \\
\hline & It is everyone's duty to answer, not just mine. & $1.24 \%$ \\
\hline \multirow{3}{*}{$\begin{array}{l}\text { Type B: teacher's questioning } \\
\text { strategy }(13.69 \%)\end{array}$} & $\begin{array}{l}\text { Teacher will pick someone in the end if no one raises } \\
\text { hand. }\end{array}$ & $7.05 \%$ \\
\hline & Too little time is given for thinking. & $4.15 \%$ \\
\hline & $\begin{array}{l}\text { Teacher always asks boring questions, and there is no } \\
\text { need to answer them. }\end{array}$ & $2.49 \%$ \\
\hline \multirow{2}{*}{$\begin{array}{l}\text { Type C: personal reasons } \\
\qquad(12.03 \%)\end{array}$} & The topic is unfamiliar to me. & $9.54 \%$ \\
\hline & $\begin{array}{l}\text { Answering question is nothing good for me since it } \\
\text { will not affect my grades. }\end{array}$ & $2.49 \%$ \\
\hline \multirow{3}{*}{$\begin{array}{l}\text { Type D: cultural attitudes } \\
\qquad(46.06 \%)\end{array}$} & $\begin{array}{l}\text { I am accustomed to receiving knowledge passively } \\
\text { and there is no need to speak out. It's a prevailing } \\
\text { pattern in Chinese schools. }\end{array}$ & $21.16 \%$ \\
\hline & I will lose face if I make mistakes. & $19.09 \%$ \\
\hline & Speaking out actively is like showing off. & $5.81 \%$ \\
\hline Type E: environment (14.52\%) & Class atmosphere is too depressing. & $14.52 \%$ \\
\hline
\end{tabular}

Table 1 presents 13 common reasons for reticence in college EFL classes in 5 types. It was found that diffusion of responsibility caused $13.68 \%$ students' reticence, as much as that of teachers' questioning strategy. Notably, cultural attitudes, which rated at $60.58 \%$, came top in the list of reasons for students' reticence.

The first sign in diffusion of responsibility is fluke mentality. Because teacher's question is given to forty students in the class, students will think that they have a low probability of being picked, thus it is not their business to answer the question. In the interview, when we mentioned that the teacher might ask someone to answer directly if no one volunteered, student B said without hesitation, "I won't be picked for there are so many classmates". Then we asked, "Why do you choose not to answer when you actually know the answers?" Half of the students interviewed showed their dependence on a few more active students in the class. But most of these descriptions came up after their second thought, what they mentioned most were their learning habits and 
English level.

The second sign in diffusion of responsibility is herd mentality. When students see that most students are indifferent to the teacher's questions, they deem it appropriate to follow suit. What's worse, the silence of most students even affects those who initially want to answer the question. In the interview, three students admitted that the influence of classmates on their willingness to speak was very large. Student $Z$ is a very outgoing boy, but he replied, "I am always like this. Seeing nobody around is going to answer the teacher's questions, I don't think I need to answer anymore". In class observations, we found that most of the students lowered their heads habitually after being asked a question. A small number of students would look around before raising their hands hesitantly. Interestingly, once someone answered the question, many students appeared relieved, probably because they have released the pressure of being picked by the teacher.

In conclusion, diffusion of responsibility did play a role in reticence in college EFL class but not a dominant role.

\subsection{Gender and Diffusion of Responsibility}

To find out whether there are any associations between gender and diffusion of responsibility, a Spearman's correlation was conducted. It was found no correlation existed between gender and diffusion of responsibility ( $\mathrm{r}$ $=.004, \mathrm{p}=.972)($ Table 2).

Table 2. Spearman's correlation between gender and diffusion of responsibility

\begin{tabular}{ccccc}
\hline & & & Gender & Diffusion of responsibility \\
\hline \multirow{3}{*}{$\begin{array}{c}\text { Spearman's } \\
\text { rho }\end{array}$} & Gender & Correlation coefficient & 1.000 & .004 \\
& & Sig. (2-tailed) &. & .972 \\
& & $\mathrm{~N}$ & 100 & 100 \\
\cline { 2 - 5 } & Diffusion of & Correlation coefficient & .004 & 1.000 \\
& responsibility & Sig. (2-tailed) & .972 &. \\
& & $\mathrm{~N}$ & 100 & 100 \\
\hline
\end{tabular}

The interview results showed the same trend. Since only two male students were willing to be interviewed, the small number of samples would affect the generalizability of the findings to some extent. Among them, student D was a special boy who had many original ideas. Diffusion of responsibility only accounted for a small proportion of his silence in class while interest was the main reason. Another male student, Z, was more susceptible to diffusion of responsibility. Among the eight female students interviewed, three expressed their dependence on other students' active participation. When we asked them to rank the reasons for their reticence in the order of impact on them, diffusion of responsibility came lower on the list, while personality and language ability were the more prominent reasons.

In classroom observations, most of the female students would look down after being asked a question. But when one girl stood up to answer the question, other girls would become followers.

In summary, male and female students are equally likely to choose to be silent in class under the influence of diffusion of responsibility.

\subsection{English Proficiency and Diffusion of Responsibility}

A Spearman's correlation was performed to determine the relationship between students' English proficiency and diffusion of responsibility. The participants were categorized into three proficiency level groups according to their scores in College Entrance Exam: the high group (25\%), the middle group (50\%), and the low group (25\%). Table 3 shows there was no correlation between students' English proficiency and diffusion of responsibility $(\mathrm{r}=$ $-.030, \mathrm{p}=.769)$. 
Table 3. Spearman's correlation between English proficiency and diffusion of responsibility

\begin{tabular}{|c|c|c|c|c|}
\hline & & & $\begin{array}{c}\text { English } \\
\text { proficiency }\end{array}$ & Diffusion of responsibility \\
\hline \multirow{6}{*}{$\begin{array}{l}\text { Spearman's } \\
\text { rho }\end{array}$} & \multirow{3}{*}{$\begin{array}{l}\text { English } \\
\text { proficiency }\end{array}$} & Correlation coefficient & 1.000 & -.030 \\
\hline & & Sig. (2-tailed) & . & .769 \\
\hline & & $\mathrm{N}$ & 100 & 100 \\
\hline & \multirow{3}{*}{$\begin{array}{l}\text { Diffusion of } \\
\text { responsibility }\end{array}$} & Correlation coefficient & -.030 & 1.000 \\
\hline & & Sig. (2-tailed) & .769 & . \\
\hline & & $\mathrm{N}$ & 100 & 100 \\
\hline
\end{tabular}

The result is consistent with findings from the interviews. Table 4 shows the ten interviewees' final exam scores for the course of College English (III), their speaking ability (a combination of self-evaluation and teacher evaluation) and their rank of diffusion of responsibility among the reasons for their class reticence.

Table 4. Interviewees' rank of diffusion of responsibility among reasons for reticence

\begin{tabular}{cccc}
\hline No. & Final score & $\begin{array}{c}\text { Speaking } \\
\text { ability }\end{array}$ & $\begin{array}{c}\text { The rank of diffusion of responsibility } \\
\text { among reasons of reticence }\end{array}$ \\
\hline A & 85 (high) & Good & 2 \\
B & 75 (medium) & Medium & 3 \\
C & 78 (medium) & Medium & 3 \\
D & 75 (medium) & Medium & Diffusion of responsibility isn't one of the reasons. \\
E & 90 (high) & Good & 3 \\
F & 73 (low) & Low & After 3 \\
G & 73 (low) & Medium & Diffusion of responsibility isn't one of the reasons. \\
X & 77 (medium) & Low & 3 \\
Y & 79 (medium) & Low & 2 \\
Z & 73 (low) & Medium & 1 \\
\hline
\end{tabular}

Note. Final exam score $<75=$ low, $75-85=$ medium, $>85=$ high

Of the two students with higher scores, student A believed that classroom atmosphere was the most important reason for her silence in class. In the conversation with student $\mathrm{E}$, we found that she was a girl with special personality. She thought that her classmates had no great influence on her performance in class, but her own thoughts and emotions were responsible. Both of the students had good speaking ability, but student A who had a lower grade was affected more by the psychology of diffusion of responsibility. The five students in the medium group scoring between 75 and 80 were little affected by diffusion of responsibility. Two students with low English speaking ability said that their poor oral ability was the biggest reason for silence. Student $Y$ thought that she didn't have to answer since there were active classmates to help. D was a boy with his own ideas. He claimed that interest and efficiency are his biggest motivation. As English was not so important to him, he tended to follow suit in class. Among the three students with lower grades, student $\mathrm{G}$ believed that her rapport with the teacher determined her classroom participation. F was very introverted, and her English proficiency was low. Among the many reasons for her silence in class, the biggest reason was her extremely introvert personality. On the contrary, $\mathrm{Z}$ ranked diffusion of responsibility as the top reason for his silence.

To sum up, English proficiency levels make little difference when it comes to students' silence caused by diffusion of responsibility. The effect of diffusion of responsibility on students' reticence in class is less than that of interest and personality. 


\subsection{Question Type and Diffusion of Responsibility}

A paired-samples t-test was conducted to compare diffusion of responsibility in factual question and opinion question conditions. The results reported in Table 5 show that there was no statistically significant difference in the scores for factual question $(\mathrm{M}=.16, \mathrm{SD}=.368)$ and opinion question $(\mathrm{M}=.13, \mathrm{SD}=.338)$ conditions; $\mathrm{t}(99)$ $=.653, \mathrm{p}=.515$. These results suggest that question type did not affect diffusion of responsibility. Specifically, our results suggest that when students were asked a factual question, they were as likely to remain silent because of diffusion of responsibility as when they were asked an opinion question.

Table 5. Paired-samples t-test of question type on diffusion of responsibility

\begin{tabular}{cccccccc}
\hline Variables & $N$ & Mean & $S D$ & $C I(M D)$ & $t(d f)$ & $P$ (2-tailed) & Sig. level \\
\hline Factual question & 100 & .16 & .368 & $-.061, .121$ & $.653(99)$ & .515 & 0.05 \\
\hline Opinion question & 100 & .13 & .338 & & & \\
\hline
\end{tabular}

To double-check, we asked students in the interviews to name two or three biggest reasons for their silence when they were given both types of questions. It was found that the answers from the seven students were very similar when concerned with factual questions. "This kind of question is not interesting. No one is interested in it. And the classroom atmosphere becomes very depressing". They thought this type of questions had an only answer, which made no difference whether answered by them or fellow students. Therefore, the necessity to appoint a respondent no longer existed, giving rise to diffusion of responsibility. The other three said they were shy and afraid of making mistakes. When faced with opinion questions, except for the three introverts, the rest of the students admitted that they were afraid of making mistakes because they could not organize their language well. In addition, three students said that they did not want to express their ideas because they were not familiar with their classmates and teachers. Only student A said, "If there are multiple answers to opinion questions, there will be more people to answer and I will not be needed". In classroom observations, we found that most students were silent when factual questions were given; while opinion questions could arouse the enthusiasm of some students, breaking class silence.

To conclude, while there was no statistical evidence for any associations between question type and diffusion of responsibility, data from interviews and classroom observations seem to suggest diffusion of responsibility affects factual questions more than opinion questions.

\subsection{Class Size and Diffusion of Responsibility}

Paired-samples t-test was again performed to compare diffusion of responsibility in whole class and small group conditions. As Table 6 shows, there was a statistically significant difference in the scores for whole class (M $=.23, \mathrm{SD}=.423)$ and small group $(\mathrm{M}=.12, \mathrm{SD}=.327)$ conditions; $\mathrm{t}(99)=2.460, \mathrm{p}=.016$. These results suggest that class size really did have an impact on diffusion of responsibility. Specifically, our results suggest that when students worked as a whole class, they were more likely to choose to be silent due to diffusion of responsibility than when they worked in small groups.

Table 6. Paired-samples t-test of class size on diffusion of responsibility

\begin{tabular}{cccccccc}
\hline Variables & $N$ & $M$ & $S D$ & $C I(M D)$ & $t(d f)$ & $P(2$-tailed) & Sig. level \\
\cline { 1 - 3 } Whole class & 100 & .23 & .423 & $.021, .199$ & $2.46(99)$ & $.016^{*}$ & 0.05 \\
\cline { 1 - 3 } Small group & 100 & .12 & .327 & & & & \\
\hline
\end{tabular}

In the interviews, when asked "If the class changes to a smaller size, like 10 to 20 people, will you be more active in classroom participation?" eight students said they would be more active. But, to our surprise, their changed attitude was not because of increased responsibility but because of a more comfortable classroom atmosphere. Within a smaller class, it would be easier for students to get familiar with one another. As a result, a good rapport between classmates and teacher would enhance students' willingness to participate in class. In addition, two students mentioned that the small class size could also facilitate teachers to remember students' names, so teachers may pick someone to speak more often. But even this situation would be preferred over volunteering to speak up. All this suggests that a good rapport is able to underplay the division of responsibility. That is to say, when 
students regard their classmates and teachers as friends, they would more readily "take their responsibility". On the other hand, two students said more attention from the teacher would lead to more responsibility on each student, which would make them more nervous.

To sum up the results from the questionnaire and interviews, when there are less people around, students tend to believe that they will take on more responsibility either voluntarily or involuntarily. The effect of class size on reticence caused by diffusion of responsibility is noticeably seen. The smaller the class size, the less likely it is for diffusion of responsibility to cause reticence.

\subsection{Discussion}

The results from data analysis revealed findings both in and out of our expectations. On the one hand, it was found that most students in college EFL classes were actually under the influence of diffusion of responsibility. Yet, it has been so internalized a force that it hardly occurred to students when they were asked to recognize the reasons for their silence. As a result, students identified external factors such as classroom atmosphere and cultural attitudes more readily. This was backed up by Cheng (2000), who agreed that all factors underlying class reticence were interrelated. Data from the questionnaire found that about $50 \%$ of the students attributed their silence to "face" and the long-standing habit of listening passively, which is in accordance with the findings of Tang, Wang and Wong (2020) that reticence in higher education classroom was often identified as a "habitual behavior". In a sense, students "learn to be silent" from their previous education experiences.

In fact, the formation of the habit is largely influenced by the surroundings. Everyone's silence eventually leads to depressing classroom atmosphere, creating a vicious circle. In traditional college EFL classes, there were only a few output tasks requiring cooperation or presentation, which led many students to become passive observers while ignoring the importance of class participation. Moreover, they grew less able to see their responsibility to participate the longer they stayed in such a deforming learning environment, making it even harder to break their habitual silence. This is how diffusion of responsibility becomes a source of depressing classroom atmosphere and shapes students' opted silence in class.

There was a statistically significant difference by class size in diffusion of responsibility with regard to the reasons for class reticence. This explains why college EFL classes in China, typically with 40-50 students in a class, are plagued by students' silence. In addition, Chinese students have a strong sense of collectivism. They get used to being in a familiar environment, where they tend to feel comfortable and take less initiative. As a result, the responsibility of class participation is shared by a large group of students, while less responsibility is felt by individuals.

On the other hand, though there is no statistical evidence to prove our speculations about the relationships between diffusion of responsibility and gender, or English proficiency, or question type, the findings from interviews and classroom observations still provide useful reference when teachers find themselves stuck in a silent class.

It is found that whatever their personality, interest, or English proficiency, male and female students are equally susceptible to diffusion of responsibility. The one who took the lead in breaking class silence was usually followed by other students who were hesitating about whether to speak out in class. In this light, students with high English proficiency are usually the ones taking the lead. They generally have confidence in English speaking and take on more responsibility in class participation. Students with medium English proficiency are the ones who become potential followers in class activities. They make up the majority of a class and their willingness for class participation could swing depending on the class atmosphere and how much responsibility they feel. For those with poor English proficiency, they may well see the responsibility in class participation, but their inadequate language ability leads them to shy away from any risk of exposing their incompetency in class.

With opinion questions, students were relatively less likely to be silent because of diffusion of responsibility. This is because the uniqueness of individual expression cannot be replaced and therefore is more valued by students. On the contrary, a question with a fixed answer often gives the impression that it is nobody's obligation to answer it since anyone could answer it.

Summing up, learning habits and cultural attitudes contribute to diffusion of responsibility in class, and individual behaviors then lead to the formation of the learning environment, which in turn brings about a collective tendency towards opted silence in class.

\subsection{Implications}

To contain diffusion of responsibility in college EFL classes, teachers may adjust the way they assign tasks in classroom activities. 
To begin with, in whole-class question and answer sessions, teachers can simply appoint students to respond when it comes to factual questions. More importance should be given to opinion questions. As Tang, Wang and Wong (2020) suggested, open-ended classroom discussion without standard answers may help reduce silence in some way. In terms of task type, there should be an increase in the number of group discussion and dialogue exercises, which involve a stronger sense of responsibility on individual students. Another consideration is that students are more willing to challenge their peers, especially in small groups rather than in front of the whole class (Shao and Gao, 2016). Furthermore, more opportunities can be given to those with medium English proficiency level since they make up the majority of reticent students and might change their minds more readily than students of high and low proficiency levels. In addition, teachers can designate different questions to each group where one of the group members is going to be asked to present their discussion results afterwards. Under this circumstance, the probability of each student answering the question becomes a quarter, not only ensuring an increased sense of responsibility but also mobilizing more students to participate in class.

Also, it is important to remember that students' motivation to participate in class is either benefit or interest. For instance, students have a desire to communicate with others for the purposes of "improving oneself" (Liu, Zhang and $\mathrm{Lu}, 2011$ ). So, only when the learning content interests or benefits them, will they be willing to take it seriously. "Helping learners create meaning rather than helping them develop perfectly grammatical structures or acquire native-like pronunciation", as Li and Liu (2011) emphasized, shows the great importance of validity of class interaction. Therefore, classroom activities in college EFL classes are supposed to target meaningful communication rather than the mechanics of the language.

Based on students' suggestions from interviews, we come up with some original solutions that might help improve EFL class atmosphere in other ways. First, teachers can increase students' participation through coercion first, and then slowly shift to spontaneous behavior. Habits are hard to change, so it will take an outside force to break them. By clearly assigning questions to each student, they will gradually build up the awareness that the class requires their participation. Li and Liu (2011) held the same opinion:

Once the reticent student learns that he/she should not be only a good listener but also an active negotiator and he/she, like anyone else, is responsible for contribution in group activities, the individual might feel obliged to participate and fulfill his/her role as a second language learner.

At the end of the questionnaire, many students mentioned that they wanted the class to be more interesting. Therefore, teachers should make a point of designing tasks to stimulate students' interest, such as cooperative group learning, debates on current topics, and workshops on real-life communication skills. These activities may help students feel that they are spending their time doing meaningful things instead of learning for the sake of credits.

Secondly, it is urgent for teachers to build rapport and trust with students. Students' willingness to communicate may change according to the degree of rapport with the interlocutor (Cao and Philp, 2006). Meeting students' learning needs and listening to their thoughts can increase intimacy. In class or after class, teachers can chat with students as friends. Taking the initiative to share personal experiences can display the teacher's sincerity and draw students closer. Consequently, the feeling of hierarchy between teachers and students will be weakened.

To help students overcome their fear of making mistakes, it is advisable to create a safe and supportive learning environment in which students can feel at ease (Carter and Henrichsen, 2015). If students and teachers develop a friendly relationship, more students will be willing to cooperate, whether it is due to respect or sincerity, and take the initiative to participate in classroom activities.

Similarly, the relationship between students in a class largely determines classroom atmosphere. Students in college EFL classes come from different majors and do not know each other well. In view of this, teachers can first let the familiar ones sit together, and then change seats in groups (at least in pairs) instead of individuals since the efficiency of getting familiar in form of groups is much higher than individuals. After classmates become familiar, the classroom environment will become harmonious, and students will have greater motivation and courage in a comfortable learning environment.

\section{Conclusion}

\subsection{Summary}

The current study first ascertained the existence of diffusion of responsibility as a reason for college EFL class reticence. Then it explored the relationship between diffusion of responsibility and gender, or English proficiency. Further, it investigated differences by question type, or class size in diffusion of responsibility. It was found that diffusion of responsibility was indeed one of the reasons for reticence in college EFL classes, but not a dominant 
one. Additionally, a good or poor rapport with fellow students and the teacher was also a crucial factor in students' willingness for class participation apart from cultural attitudes and classroom atmosphere. No relationships were found between diffusion of responsibility and gender, or English proficiency. Nor was there significant difference by question type in diffusion of responsibility. However, there was indeed a statistically significant difference by class size in diffusion of responsibility.

Based on the results from this empirical study, several pedagogical implications could be put forward. On the one hand, more attention could be given to students with medium English proficiency since they are likely to swing between active and inactive participation in class. Asking opinion questions would help to mitigate diffusion of responsibility in class reticence. On the other hand, building a good rapport between students and teacher as well as between students is one of the biggest breakthrough points to promote greater classroom participation. Both teachers and students need to break the inherent habits in order to add meaning to every class. For teachers, clear designation of in-class tasks and positive relationships with students will make a difference. For students, promoting the sense of responsibility and discovering the value of each class will help in the final analysis.

\subsection{Limitations and Future Directions}

The limitations of this study may include but are not confined to the following. First, the small size sample in the present study limited the scope for generalization of the research findings. Further study involving larger samples of participants from both genders and different year levels are needed to confirm the findings of the present study. Second, the design of the questionnaire leaves space for improvement. Questions aiming at underlying reasons for students' silence could be developed in a 5-scale questionnaire in order to yield more accurate statistics. Third, the duration of classroom observations were too short to generate more details. Future study could spend more time on classroom observations.

\section{References}

Alemi, M., Tajeddin, Z. \& Mesbah, Z. (2013). Willingness to communicate in L2 English: impact of learner variables. Research in Applied Linguistics, 4(1), 42-61.

Beyer, F., Sidarus, N., Bonicalzi, S. \& Haggard, P. (2017). Beyond self-serving bias: diffusion of responsibility reduces sense of agency and outcome monitoring. Social cognitive and affective neuroscience, 12(1), 138-145. https://doi.org/10.1093/scan/nsw160

Cao, Y. \& Philp, J. (2006). Interactional context and willingness to communicate: a comparison of behavior in whole class, group and dyadic interaction. System, 34(4), 480-493. https://doi.org/10.1016/j.system.2006.05.002

Carter, S. J. \& Henrichsen, L. E. (2015). Addressing reticence: the challenge of engaging reluctant adult ESL students. Journal of Adult Education, 44(2), 15-20.

Cheng, X. (2000). Asian students' reticence revisited. System, 28(3), 435-446. https://doi.org/10.1016/S0346-251X(00)00015-4

Denzin, N. K. (1989). The research act (3rd ed.). Englewood Cliffs, NJ: Prentice Hall.

Grant L. Osterman. (2014). Experiences of Japanese university students' willingness to speak English in class: A multiple case study. SAGE Open, 4(3), 1-13. https://doi.org/10.1177/2158244014543779

Harmer, J. (2000). How to teach English. Beijing: Foreign Language Teaching and Research Press.

Harumi, S. (2011). Classroom silence: voices from Japanese EFL learners. ELT journal, 65(3), 260-269. https://doi.org/10.1093/elt/ccq046

Hu Qingqiu, Nielson Ed. \& Chen Wei. (2004). A survey on the questioning pattern of college English teachers. Foreign Language World, 6, 22-27.

Karp, D. A. \& Yoels, W. C. (1976). The college classroom: Some observations on the meaning of student participation. Sociology and Social Research, 60, 421-439.

Kassin, S., Fein, S., Markus, H. R. \& Burke T. (2013). Social psychology. Toronto: Nelson Education.

Li, H. \& Liu, Y. (2011). A brief study of reticence in ESL class. Theory and Practice in Language Studies, 1(8), 961-965. https://doi.org/10.4304/tpls.1.8.961-965

Liu, M. \& Jackson, J. (2009). Reticence in Chinese EFL students at varied proficiency levels. TESL Canada Journal, 26(2), 65-81. https://doi.org/10.18806/tesl.v26i2.415

Liu, M., Zhang, W. \& Lu, Z. (2011). Reticence and anxiety in Chinese university ESP poetry class: A case study. 
Journal of Language and Culture, 2(2), 20-33.

Peng, J.E. (2014). Willingness to communicate in the Chinese EFL university classroom: An ecological perspective. Multilingual Matters. https://doi.org/10.21832/9781783091560

Shao, Q. \& Gao, X. A. (2016). Reticence and willingness to communicate (WTC) of East Asian language learners. System, 63, 115-120. https://doi.org/10.1016/j.system.2016.10.001

Soo, R. S. \& Goh, H. S. (2013). Reticent students in the ESL classrooms. Advances in Language and Literary studies, 4(2), 65-73. https://doi.org/10.7575/aiac.alls.v.4n.2p.65

Tang, X., Wang, Y. \& Wong, D. (2020). Learning to be silent: examining Chinese elementary students' stories about why they do not speak in class. Language, Culture and Curriculum. https://doi.org/10.1080/07908318.2020.1715999.

Wang Jiang \& Zhang Jing. (2008). The solution and strategy for college English classroom silence. China University Teaching, 1, 81-84.

Wu Ting. (2016). On correlation between teachers' discipline strategy and college students' willingness to communicate in English. Foreign Language Education, 37(3), 61-65.

Zhang Huiqin \& Zhang Kun. (2009). On silence in college English classrooms. Foreign Languages in China, $6(2), 78-84$.

Zhang, X. \& Head, K. (2010). Dealing with learner reticence in the speaking class. ELT journal, 64(1), 1-9. https://doi.org/10.1093/elt/ccp018

\section{Copyrights}

Copyright for this article is retained by the author(s), with first publication rights granted to the journal.

This is an open-access article distributed under the terms and conditions of the Creative Commons Attribution license (http://creativecommons.org/licenses/by/3.0/). 